\title{
The Challenges Confronting the Delivery of Training and Development Programs in Saudi Arabia: A Critical Review of Research
}

\author{
Majed Bin Othayman ${ }^{1,2^{*}}$, Abdulrahim Meshari1,2, John Mulyata1, Yaw Debrah ${ }^{1}$ \\ ${ }^{1}$ School of Management Department, Swansea University, Swansea, United Kingdom \\ ${ }^{2}$ Business School, King Khalid University, Abha, Kingdom of Saudi Arabia \\ Email: ^844680@swansea.ac.uk, 844520@swansea.ac.uk, john.mulyata@swansea.ac.uk, y.a.debrah@swansea.ac.uk
}

How to cite this paper: Othayman, M. B., Meshari, A., Mulyata, J., \& Debrah, Y. (2020). The Challenges Confronting the Delivery of Training and Development Programs in Saudi Arabia: A Critical Review of Research. American Journal of Industrial and Business Management, 10, 1611-1639. https://doi.org/10.4236/ajibm.2020.109103

Received: August 18, 2020

Accepted: September 26, 2020

Published: September 29, 2020

Copyright $\odot 2020$ by author(s) and Scientific Research Publishing Inc. This work is licensed under the Creative Commons Attribution International License (CC BY 4.0).

http://creativecommons.org/licenses/by/4.0/

\begin{abstract}
This research aims to identify the challenges confronting the delivery of training and development in the context of Saudi Arabia. Saudi Arabia is a country which is currently in a transformational phase, triggered by domestic factors like Vision 2030 and global factors. Through a process known as Saudization, the government of Saudi Arabia seeks to improve the quality of human resource in the country and provide the maximum opportunities to its youth that constitutes a significant part of its population. To this end, the government is heavily investing in training and development programs and the education sector. This study collects secondary data from government documents, databases, articles, reports, books, and previous studies undertaken by the government to measure the effectiveness of its training and development programs. Various findings have been summarised from the perspective of challenges confronting the delivery of training and development programs in Saudi Arabia.
\end{abstract}

\section{Keywords}

Training and Development, Programs, Training Outcomes, Training Hurdles

\section{Introduction}

As is the cases in other countries within the Gulf, Saudi Arabia faces its challenges in the area of training and development (T\&D). For instance, KPMG (2019) reports that Saudi Arabian organizations face substantial H.R. challenges due to turbulent external environmental factors: demographical, legislative, technologi- 
cal, and economical. Moreover, the 2030 reforms vision announced in 2016 exerted pressure on Saudi organizations to change. This a situation that has led to many changes within organizations in Saudi Arabia (Al-Hanawi et al., 2019). Training and development is a crucial concern for policymakers because of its importance in organizational success (ibid). According to a report from the General Authority for Statistics (2018), Saudi Arabia had a population of 33.4 million people in 2018. Most of its population is below 50. The illiteracy rate in the kingdom has decreased dramatically from $60 \%$ in 1972 to $5.6 \%$ in 2018 . With regards to the labour market position, 12,688,042 individuals were employed in 2018. Seventy percent of the employed work in the private sector (KPMG, 2019). The reported demographics show an increased potential in the Saudi workforce to learn and grow. Also, it has been noted that the Saudi Arabian private sector is making a considerable contribution to the provision of employment and development opportunities. However, expatriates hold the majority of employment in the private firms, comprising of $80.4 \%$ (Saudi Arabian Monetary Authority (SAMA), 2019).

Achoui (2009) discusses the various reasons behind the higher employment levels of expatriates in Saudi private firms based on the study of Ramady (2010). The main reasons include high cost of Saudi labour, negative attitudes and perceptions toward low status or manual jobs among Saudi citizens, foreigners (expatriates) are more understanding and well-organized as compared to Saudis, expatriates easily accept contract positions. In contrast, Saudis require job tenure, and they are low in English proficiency and generally lack appropriate technical skills for the job. Saudi workers are selective when it comes to the locations where they will work. Achoui (2009) adds that Saudi organizations face two significant challenges: a shortage of trained professionals and a greater reliance on expatriates or foreigners. Therefore, expertly designed and delivered training and development programs might change the situation in future.

Most firms invest heavily in training and development programs to improve organizational performance (Baum, 2007). The Saudi Arabian government is also taking the necessary initiatives to develop its human resource and increase the literacy rate in the country. For this purpose, US $\$ 51.73$ billion has been allocated toward education and human resource development in the 2020 budget from a total budget of $\$ 272$ Billion (Matthew Amlôt, 2019). The reason behind this huge allocation is to encourage Saudi labour to contribute to the growth of the local economy and lower the unemployment rate in the country. Moreover, due to the government's new drive to generate opportunities for the young Saudi population (Saudization), there is a dire need to provide practical training and development facilities in-country. Generally, training and development programs are considered a global phenomenon to control gaps in performance (Mwita, 2000). Considering that human resources are an essential and unique resource of a firm, they shape the intellectual property of a firm upon which it can get a competitive advantage over its competitors (Beardwell \& Claydon, 2010). This 
effectively delivered training and development programs facilitate a firm's to building and improvement of employees' competence to deal with global challenges.

Training delivery is no stranger to practitioners or scholars in human resource development (HRD) and performance improvement. Among the learning and development problems that often face organizations, supporting learners to use their new knowledge and skills to improve performance is an ongoing challenge. Research shows that organizations must address the cognitive, psychological, behavioural, and cultural aspects of job performance to enhance training applications. Strategies that positively impact training delivery include practices that affect learner characteristics such as motivation and self-efficacy, training designs that align content with work tasks, and work environments that provide opportunities for on-the-job practice. Although these practices have been widely supported in existing literature (Alvarez et al., 2004; Baldwin \& Ford, 1988; Bartlett \& Kang, 2004; Burke \& Hutchins, 2007; Grossman \& Salas, 2011), the limitation indicates that the data often relies on reports of managers or trainees and tend to overlook the views of training professionals who are closely involved in multiple stages. Trainers, performance improvement and human resource development professionals, and training managers may affect successful training application and its processes. Training professionals have specific capabilities in identifying performance needs, designing and delivering training, and working with other stakeholders to support training delivery and evaluate training results. Taking strategies and methods that training professionals consider effective to expand the research base to clarify methods that can support training delivery into consideration is vital. The purpose of this study is to describe best practices to support training delivery from the perspective of training professionals. This paper extends the work of previous research (Burke \& Hutchins, 2007), which compares the practices reported by trainers with established training transfer models.

We summarise the existing literature to highlight the contributions of existing research. Our contribution also includes extracting research results on the subject. We provide data on training and development effectiveness and its effective delivery. The paper specifically discusses the need for effective design features to provide training programs, capacity development, recruitment, development and retention. First, this review of literature is conducted at a global level and then it is narrowed down to the Saudi Arabian context, assuming that training and development practices are similar throughout the world. Second, it reports best practices from the perspective of a trainer and will provide a comparative view with existing job mobility that focus on the trainee, manager, or peer perspective in survey report data. This study gathers the different aspects of all stakeholders in a particular organization. It expands the literature by reporting on training professionals' experience in transferring best practices. Besides, determining the trainer's perspective helps to address the gap between research 
and practice by reviewing comprehensive literature. Training professionals play various roles in supporting the learning and performance of the organization, and current research suggests that training delivery requires participation in the design, implementation, and evaluation stages of the training process.

This paper has several sections. The first section presents the introduction and puts the subject under study in context. Section 2 contains the background, and Section 3 delivers the review of literature on effective design characteristics, capacity development, recruitment, development and retention in Saudi as well as the international context, the fourth section evaluates the various training programs, mainly focusing on entrepreneurial education. Lastly, the paper reports the findings and conclusions of the study.

\section{Background}

The history of training and development research dates back to the early 1900s and has a long tradition in applied psychology. Over the years, not only has an interest in this subject increased, but the science and practice of training and development have also changed dramatically. As the nature of work has changed, training goals have expanded from improving the efficiency of simple manual tasks to providing employees with the skills they need to perform complex and dynamic tasks. Once supervisors have received vocational training (Kraiger \& Ford, 2014), advances in technology will make on-demand learning possible and can be done almost anywhere, anytime. Moreover, Noe et al. (2014) argued that the role of training and development has expanded to today, not only as a means of empowering individuals but also as a valuable means of improving team efficiency and gaining a competitive advantage for the organizations. This shift is accompanied by continuous development and a growing body of knowledge across various disciplines, including military psychology, industrial/organizational psychology, cognitive psychology and human factors, which has facilitated the design and provision of training and develop a deeper understanding.

Drost et al. (2002) studied training and development practices across nine countries and regions (Canada, Australia, Japan, Mainland China, Indonesia, Korea, Taiwan, the United States, and Mexico) to identify the universality of training and development practices. He reviewed prior literature on training and development and concluded that there no universal practices exist in studied countries. However, there was a significant similarity in prevailing T\&D practices due to cultural values and industry trends.

Galvão et al. (2020) advances the argument that entrepreneurship education and training programs could have many effects in low-density areas, including local investment and creation of new businesses, employment and specialized services. The same author further commented that the need to involve different regional stakeholders in entrepreneurship programs to generate new companies that have a positive impact on local and regional development requires effective training and development. 
Substantial limitations associated with existing empirical research on training and development across nations, impede organizations' capabilities to design and implement effective HRM practices within and mainly across countries (Drost et al., 2002). Ongoing employee development is critical to the short- and long-term success of every business, profit, or non-profit organization (Becker, 1962; Pittam, 1987). Training and development in the workplace are vital because of a vicious circle starting from the time they are in university. For instance, many college students in Saudi Arabia do not receive the information and support they need to persevere and graduate. So, they need training and development in the workplace. This is mainly due to the lack of training and the development of academic staff in these universities. There is no doubt that the long-term benefits of training and development programs for academic staff outweigh the direct costs. Coordinated academic training and development are important because all students, regardless of their curriculum, should stay in touch with a knowledgeable and up-to-date teacher or tutor to help students master the policies, procedures, theories and resources needed to succeed in their studies. Therefore, training and professional development of academic staff can increase creativity in job performance. Ignoring the training and professional development of academic staff affects not only students but also institutions that bear the cost of reduced efficiency. It is on this basis that this paper delivers results on the impact of training and development on the academic creativity of Saudi universities to stimulate critical or extended analysis of the subject.

\subsection{Training and Development Programs in Saudi Arabia}

Saudi Arabia is a kingdom based on the Islamic system and laws that regulate all of the public as well as private institutions. Like other Arab countries, Saudi Arabia heavily relies on expatriate labour to meet its development objectives due to lack of needed capabilities in local human resource. The acute shortage of necessary skills required for development in local human resource imposes a challenge on the Saudi government, leading it to take a range of steps for human resource development. Consequently, the GOTEVOT (1994), a Manpower council directly under the jurisdictions of Prime Minister Office, was established for workforce planning in the country to meet with this challenge.

The government has taken multiple steps to support human resource development in the kingdom. For instance, a US $\$ 51.73$ billion budget was allocated towards education and human resource development. The country's education system is also improving gradually, as is shown in Graph 1(a) and Graph 1(b) below.

To achieve the Saudi Arabia 2030 vision, the kingdom has launched 13 national human resource development plans. The most prominent of these is the $2020 \mathrm{Na}-$ tional Transformation Plan, which includes many initiatives in line with the national development themes. Training and qualification of human capital in Saudi Arabia to reduce the gap between supply and demand in the industry is an integral part of this plan. The development of the local I.T. industry and the transition 
Saudi Arabia MOF Projection: Government Budget: Expenditure: Human Resource Development

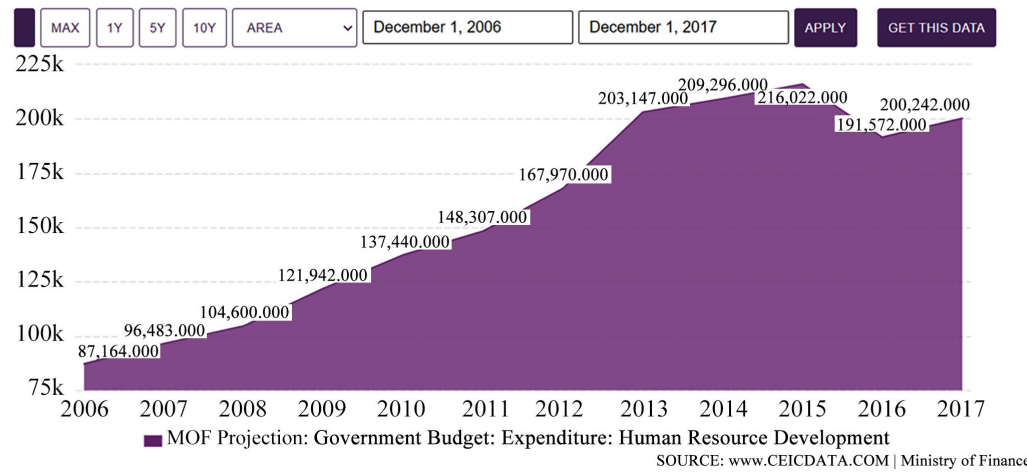

(a)

Number of students in Saudi Arabia from 2013 to 2017

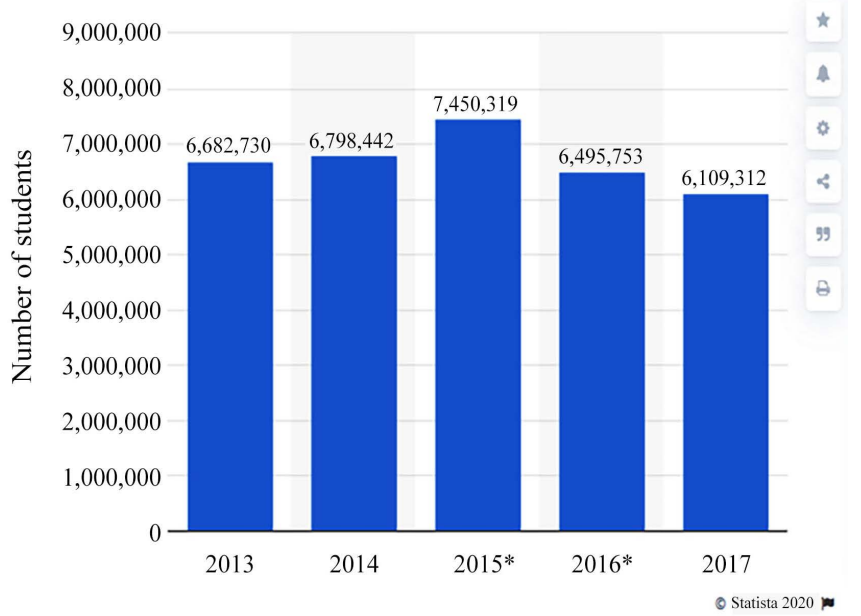

(b)

Graph 1. (a) (b): Improvements in the Saudi Arabian education system.

to a new stage of foreign I.T. products based on increasing the production of local technology is also an important aspect. The plan also seeks to create new competition in the brand market and increase the I.T. industry's contribution to GDP. It is expected that the plan will facilitate an environment for attracting investment, integrating digital work at the national level, developing and activating the government on a unified infrastructure, developing and stimulating e-commerce, and accelerating the restructuring of the postal sector and the privatization process.

The government of Saudi Arabia is heavily emphasizing the training and development programs under Vision 2030. To implement the concept of Saudization, the government has taken different initiatives. One is the launch of the Noor program that is a school administration system that is powered by advanced technology. The system is designed to bring together teachers, students, and parents in schools that come under the ministry of education. The particular objectives of the program include the initiation of a comprehensive school administration system, extending the efficiency and effectiveness in the educational 
system, timely and accurate data management, transparency, and linking KSA schools with the ministry of education.

The Nitaqat program (also known as Saudization Motivation Program) is the latest form of the Saudization steps taken by the government for the private sector. The program offers incentives to firms for preferring Saudi workers on the jobs under six categories: Yellow (firms that have not achieved the Saudization rate yet), red (firms with the lowest Saudization rate), low green (the Saudization rate falls within low third), medium green (firms falling in the middle third rate of Saudization), high green (the Saudization rate falls within top third), and platinum, based explicitly on the firm's Saudization rate. The program requires private companies to ensure the recruitment of at least $30 \%$ of employees from Saudi nationals rather than only hiring expatriates. The Ministry of Labour and Development is compelling the firms not to recruit non-Saudi employees unless in the event of the non-availability of national labour qualified to perform the required tasks. The same ministry concluded from different surveys and researches that the recruitment of expatriate workers is necessary due to factors like lack of necessary skills among Saudi employees, the disinclination of Saudi workers to take some occupations or jobs and inability to recruit a Saudi national due to any other reason. However, the overreliance on expatriates has become a challenge for Saudi Arabia. Therefore, Nitaqat is not only aligned with Saudi Vision 2030 and the National Transformation Program but also serves a vital role in strategic transformation program and different initiative of the Ministry of Labour and Development like labour market performance, proper job provision, provision of safe and attractive jobs to the Saudi Arabians, minimization of non-productive employees, effective placement of Saudi nationals, reducing the dependence on expatriates, and lowering the unemployment rate.

The third initiative is Taqat, a national labour gateway, an initiative of the Ministry of Labour and Social Development, Human Resource Development, and the Ministry of Civil Service. This is a platform bringing private and public sector employees and employers together to offer efficient and effective services for employing and training to increase stability and upgrading the Saudi people and providing equal opportunities for everyone. Taqat integrates various services like the e-portal facility for job seekers, private employer and government firm's registration, a C.V. management system, job posts management and program benefits management, customer service management, e-matching mechanism, and training service management.

\subsection{Human Capital Development Programme}

The Saudi Arabian Recruitment Program (KSARP) provides a large number of career opportunities for junior and intermediate professionals in Saudi Arabia, allowing them to join the World Bank Group (IBRD, IDA, IFC, MIGA, and ICSID) for one to two years. This program is co-funded by the Ministry of Finance of Saudi Arabia and the World Bank Group (WBG), enabling participants 
to gain valuable insights, opportunities, and experience from the perspective of the World Bank Group. At the same time, the participants helped achieve the core goals of the World Bank Group: capacity building, and diversity and professional development. Program participants acquired new skills and enhanced existing skills while sharing knowledge and gaining new perspectives.

\subsection{Programme Design Characteristics}

According to Baldwin and Ford (1988), training design received the most research attention for quantifying the results of the entire study. Existing meta-analysis research focuses on design features such as over-learning (Driskell et al., 1992), practice (Arthur et al., 1998), and training delivery methods (Arthur et al., 2003; Sitzmann, Kraiger, Stewart, \& Wisher, 2006). Also, two quantitative reviews were conducted for specific training methods for behaviour modelling (Taylor et al., 2005) and error management training (Keith \& Frese, 2008). Berry \& Morris (2005) argued that the ultimate goal of training should be an active transfer of knowledge to the organization. However, estimates indicate that only about $10 \%$ of learning has been transferred to job performance (Holton III et al., 2000; Georgenson, 1982; Kupritz, 2002), which has led human resources professionals to scramble to prove their work and sponsor value for training plans (Tompkins, 2002; Huselid et al., 2001). As a result, training in public and private organizations has shifted from examining learning outcomes to focusing on personal outcomes such as self-esteem, self-efficacy, performance evaluation, performance improvement, and organizational performance outcomes such as profitability, revenue growth, shareholder value (Baldwin \& Ford, 1988; Burke \& Baldwin, 1999; Tompkins, 2002; Richman-Hirsch, 2001).

According to existing training literature, several training design factors influence the transfer of training: instructional techniques and learning principles (e.g. Alvarez et al., 2004), self-management and relapse prevention strategies (e.g. Tziner et al., 1991; Wexley \& Nemeroff, 1975), and goal setting (e.g. Gist et al., 1989). Thus, organizations should design their training programs to include such factors that increase the likelihood of transfer. According to, Learning Transfer System Inventories (LTSI) measures such factors like transfer design. Transfer design refers to the degree to which training has been designed and delivered in such a way that provides trainees with the ability to transfer learning back to the job (Holton et al., 2000). Holton et al. (2000) argue that part of transfer design is the degree to which training instructions match job requirements. Trainees are more likely to transfer the training content to the work context when they perceive that the training program was designed and delivered in a way that maximizes the trainee's ability to transfer the training to the job (Holton, 1996, 2005). Consequently, when trainees have previous knowledge and practice on how to apply the newly learned knowledge and skills to the job and when training instructions are congruent with job requirements, an increased likelihood of transfer should exist. 
In their literature review, Burke \& Hutchins (2007) identified need analysis, learning goals, content relevance, practice and feedback, over-learning, cognitive overload, active learning, behavioural modelling, error-based examples, selfmanagement strategies, and technological support variables as training design and delivery factors that were used by the training transfer researchers. Content relevance or content validity of the training goals and materials to the transfer tasks was critical in training transfer. Bates and Poole (2005) investigate the predictive abilities of the factors affecting training transfer and reveal the Thai managers perceived that content relevancy is a primary factor predicting successful transfer.

Table 1 below summarises some studies focusing on various elements of training and the results that these studies arrived at.

\subsection{Establishing the Capacity Development Programme}

The concept of capacity building (which was later replaced by capacity development) received attention in the development discourse of the 1990s, as a better way of "development." Although the academic literature on capacity development has been scarce over the past few decades, references to capacity development have increased dramatically during the 1990s and beyond. Multilateral and bilateral development organizations have emphasized the importance of capacity building in their strategy documents. For some of them, capacity building is the primary purpose of their development assistance. Over the past two decades, the concept of capacity development has changed, from a focus on human resource development and individuals to a concept that encompasses individuals, organizations, and the broader society in which they work. Importantly, it has been recognized in development discussions that sustainable capacity development is an endogenous process driven by those who will develop their capabilities. This means that although external assistance can play an important role in capacity building, externally imposed measures are unlikely to develop sustainable capabilities. Therefore, sustainable development requires a demand-oriented and results-oriented approach, while technical assistance is usually supply-oriented and investment-focused.

The World Bank (1998) defined capacity as "the combination of people, institutions and practices that permits countries to reach their development goals." The same organization adds, "Capacity building is an investment in human capital, institutions and practices." Capacity development is an umbrella term covering concepts like institution building, institution development, and human resource development, improving management administration and institutional strength (Lusthaus et al., 1999). According to Linnel (2003) capacity development may be related to organizations through several elements: governance, mission and strategy, leadership, administration (including financial management, human resources, and legal matters), fundraising and income generation, programme development and implementation, partnerships and collaboration, 
diversity, advocacy and policy change, evaluation, marketing, planning, and positioning.

Table 1. Summary of studies focusing on various elements of training and their conclusions.

\begin{tabular}{llll}
\hline Study & Location & Aims & Results \\
\hline & & $\begin{array}{l}\text { Training design, individual } \\
\text { characteristics and work } \\
\text { environment as determinants } \\
\text { of transfer of training to the } \\
\text { Velada et al. (2007) } \quad \text { India }\end{array}$ & $\begin{array}{l}\text { The results indicate that to strengthen the transfer of training, } \\
\text { organizations should design training to enable trainees to have the } \\
\text { ability to transfer learning, strengthen trainees' belief in their transfer } \\
\text { ability, ensure that training content is retained over time, and provide }\end{array}$ \\
& $\begin{array}{l}\text { appropriate information about employee work feedback on performance } \\
\text { after training activities. }\end{array}$ &
\end{tabular}

Lim \& Morris (2006) $\quad$ Korea $\quad \begin{aligned} & \text { Trainee characteristics, } \\ & \text { instructional satisfaction, } \\ & \text { and organizational factors }\end{aligned}$

Results showed that trainee characteristics, instructional satisfaction, and organizational factors significantly influenced the trainees' perceived learning and learning transfer immediately after and three months following the training.

Identify the factors relating to trainee characteristics (cognitive ability, self-efficacy, motivation, perceived utility of training), training design (behavioural modelling, error management, realistic training environments) and the work environment (transfer climate, support, opportunity to perform, follow-up) that have exhibited the strongest, most consistent relationships with the transfer of training.

Taylor et al. (2005)

Behavioural modelling facilitates transfer when both positive and negative models are used, and when opportunities to practice are provided.

\section{Burke \& Hutchins}

(2007);

Heimbeck et al. (2003)

\section{Error management promotes the transfer of training by allowing trainees} to anticipate potential issues, providing them with knowledge of how to handle such problems, and highlighting the adverse outcomes that can occur if training is not transferred.

\section{Burke \& Hutchins}

$\begin{array}{ll}\text { (2007); } & \text { Realistic training } \\ \text { Kraiger (2003); } & \text { environment }\end{array}$

Kraiger (2003);

Salas et al. (2006)

\begin{tabular}{ll}
\hline & Aims to extract the data \\
& related to the target \\
population, study design, \\
characteristics of the \\
intervention, outcomes, \\
and effectiveness.
\end{tabular}

Keith \& Frese (2008)

Bell \& Kozlowski (2008)

Matachi (2006)
The study highlighted the diversity in the design of studies and the program's effectiveness evaluation.

Effectiveness of error management training: a meta-analysis

Active learning: effects of core training design elements on self-regulatory processes, learning, and adaptability. 
Competency is the ability of an organization to effectively complete tasks and maintain its capabilities over the long term whereas at individual level capacity development covers leadership, defensive skills, training/speaking abilities, technical abilities, organizational abilities, and other areas of personal and professional effectiveness. Kaplan (2000) proposes various interrelated components of capacity development, which constitute a hierarchy. Some are more important than others. The first is the conceptual framework that deals with a comprehensive understanding of the organization's domain, and without other skills and capabilities will be powerless. The second is organizational "attitude," which covers confidence in acting and confronting the world in ways that the organization believes can have an impact. Vision and strategy, constitute the third component, comprising on a purposeful organizational structure, clear roles, functions, communication channels, decision-making processes. The fourth factor focuses on personal skills and abilities. Material resources are the last. Capacity building involves a continuous process of organizational development, peer learning, training and academic research, research, publishing and grants. Capacity development brings many stakeholders altogether to achieve overall development purposes. On the other hand, capacity development is an arbitrary term with numerous meanings (Lusthaus et al., 1999).

\subsection{Capacity Development Approaches: An Overview}

The principles of classical management emphasize increasing of productivity and efficiency by designing a consistent organizational structure (Mullins \& Christy, 2010). They also focus on the division of labour and designate responsibilities and duties that promote functional principles (Mullins \& Christy, 2010). People management is one of the essential principles incorporated into traditional organizations. Focus on it has resulted in the implementation of training and development programs, benefits programs, compensation incentive programs, and improved working conditions. Higher work output and above-average performance can be measured, and higher wage rates can be used as incentives because the general assumption is that the sole purpose of employees is to increase their income. Coordination between management and employees is critical to improving quality and quantitative productivity. Role culture is the main characteristic of classical organizations, so the focus is mainly on tasks assigned by senior management. From this perspective, the organizational structure is a formal hierarchical system with an authoritarian leadership style. Its primary focus is on the organization and its needs. Interactions are only vertical, and knowledge exists among senior managers. Classic management principles support the development of organizational capabilities because they focus on improving organizational operations and facilitation of task distribution. However, these processes will not promote organizational learning, employee skills development, job satisfaction, social interaction, and effective communication between all levels of the structure, which is essential for personnel capacity building. There are four methods of capacity development: organizational methods, 
institutional methods, systematic methods, and participatory process methods.

Some of the issues with capacity development, including:

- Capacity development requires more clarity.

- There is a greater need to understand the role of time in capacity development.

- There is a need to do more research and evaluation to develop rational and logical knowledge of capacity development.

- The requirement for harmony in the purpose of capacity development.

- The need to understand the role of power in the capacity development process.

- Requires more technological advancement.

- Need to identify the need to initiate a capacity development intervention.

Some important studies discussing capacity development (Table 2)

\subsubsection{Trainee Recruiting and Development}

Flippo (1979) defined recruitment as a process that involves identifying candidates who qualify for a position in an organization and motivating them to apply for it. Stone (2005) sees recruitment as the process of attracting a group of people looking for a certain kind of job to select one or more for open vacancies within an organization. Many researchers have studied the recruitment in different settings. For instance, Barber, Wesson, Robersin, and Taylor (1999) compared the recruitment and selection practices of large and small companies. They concluded that small and large companies approach recruitment in different ways. Hornsby and Kuratko (1990) proposed that similar to large organizations, human resource management methods for SMEs have also become batter in their recruitment practises.

Ongori \& Migiro (2010) found that effective employee recruitment, selection, and retention are critical factors in any organization, which often also determines the success and sustainability of SMEs. Windolf (1986) found that companies with less than 20 employees take a loose approach to recruitment and selecting employees, which may lead to high employee turnover. According to Cook (1998), private firms usually do not spend time and discipline on an effective recruitment and selection process, which in turn may lead to reduced retention rates.

Against the background of the above reports and surveys, the growth of Saudi SMEs must not overlook the importance of employee recruitment, selection and maintenance of SME success. The current practices of businesses in Saudi Arabia, mainly family-owned businesses, must be studied to help owners/managers address challenges related to employee recruitment, selection and retention by providing improved new solutions as their limited literature or research evidence available.

\subsubsection{Elements of Successful Professional Development}

A recent review of the literature (SRI International, 2002) outlined eight critical elements of effective professional development:

1) Format: Is the mode of delivery for the training, either in the traditional format (such as a seminar) or a more innovative format (such as a research group or hands-on activity)? 
Table 2. Additional information on the training program, design, and delivery characteristics of studies included in the review.

\begin{tabular}{|c|c|c|}
\hline References & Location & Results \\
\hline Horton (2000) & China & $\begin{array}{l}\text { This article discusses ten underlying issues involved in planning, implementing, } \\
\text { and evaluating capacity development in R \& D organizations. The results show } \\
\text { that evidence in other areas highlights the importance of high-level commitment } \\
\text { and leadership, an important external environment, and effective management } \\
\text { of organizational change processes. The success of many capacity development } \\
\text { efforts is limited by the fact that they focus on technical factors and ignore major } \\
\text { social and political obstacles. }\end{array}$ \\
\hline
\end{tabular}

The review of the latest literature deepens the understanding of the concept of

Lusthaus et al. (1999);

Lavergne \& Saxby (2001)

Canada

capacity development by exploring some conceptual and practical issues related to capacity development and summarise their impact on planning, monitoring, and evaluation results. It also clarifies the implications of adopting a capacity development approach in development cooperation.

Brinkerhoff \& Peter Morgan (2014);

Govender (2016)

Segrott et al. (2006);

Gething \& Leelarthaepin (2000);

Clare \& Hawes (2001);

Iredale \& Cleverly (1998);

Australia and the United

Kingdom

Farrington (1996);

Crookes \& Bradshaw (2002)

Feldman \& Acord (2002)

United States

Pearson (2012);

Wilkes \& Jackson (2013)

Hill et al. (2003);

Tyler et al. (2019)
Mainly the U.K.

UAE
Introduces the topic of conventional conceptions of capacity development.

Much of the dynamics and interactions that result in increased capacity to achieve results, perform, and cope with complex change.

Discuss how to build a research culture in academia

the nursing department, specific strategies adopted and their results. The studies explore the issue of empowerment, describe the authors' experience in adding

research activities and fostering a research culture, including an assessment of the strategies used. The study the main obstacles to capacity building, adopt (or propose) capacity-building strategies in the literature, and considers a wide range of backgrounds. The literature provides many examples of capacity building strategies that follow future research directions.

Describes how two schools of nursing developed research activity, including support networks, strategic direction and the distribution of teaching and research loads.

Concludes that an enabling research culture is an environment characterized by research productivity, positive collegial relationships, inclusivity, non-competitiveness, and effective research processes and training. The authors' findings resonate with and provide empirical support for previous literature highlighting the importance of community and collegial relationships to research productivity.

Illustrates that developing a research culture in the academic sector promotes key aspects that require leadership, support, and effective management. Mapping primary medical research capabilities and funding, and proposing future capacity-building strategies, including building a sustainable infrastructure.

McCreaddie et al. (2018)

Various

Nind \& Lewthwaite (2018)
European
Shows that building research capacity includes supportive infrastructures, training, funded posts, and networks.

\begin{tabular}{|c|c|c|}
\hline & 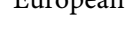 & environments. \\
\hline Crossley (2019) & Belize & $\begin{array}{l}\text { Explores how evaluation and research can aid "educational development in small } \\
\text { states" and examines the cultural aspects of "north-south collaboration". }\end{array}$ \\
\hline
\end{tabular}




\section{Continued}

Fussy (2019) Tanzania

Airhihenbuwa et al. (2015);

Owen et al. (2018)

Vallejo \& Wehn (2016)

(Poon, 2004)

Ahmad et al. (2019)

Brinkerhoff (2010)

Buqawa et al. (2018)

Al-Hanawi et al. (2019)

Hassanain (2017)
Global perspective

Global South

Developing

Countries

Pakistan

USA

Arabian Gulf

Saudi Arabia

Saudi Arabia
Outlines the inadequacy of current health research capacity in the global south, and discusses key capacity-building strategies and the factors which determine their success.

Delivers account of the development of a network to enhance research capacity in primary care, which adopted a "whole system approach" to meet the competing aims of capacity development.

Discusses collaboration between southern nations, including issues of cultural difference and ensuring that the local community's benefit from involvement in research studies.

Examines the strategies that research managers in developing countries can adopt to build research capacity within specific Organizations.

Research outcomes depict that supervisory support and OSCD development does not impact significantly on employee's performance in the banking sector. In contrast, the capacity building of an individual employee leads to enhancement of their performance.

The model identifies three dimensions that can be used to characterize interventions to build capacity: the amount of time required, the degree of difficulty and complexity, and the scope and depth of the change involved.

The purpose of this article is to review and reflect on the development and transformation of the Graduate Program in Technology Management from 1990 to 2015 at Arabian Gulf University. It discusses the characteristics of systems thinking, the links between academia and industry, research methods, problem-based learning, technology policy, social innovation, effective online learning, critical thinking and communication skills.

Saudization and adoption of the "Nitaqat" programme have played an effective role in advancing Saudization goals in the private sector and have absorbed a huge space for well-trained Saudi youths in the healthcare sector.

This case study shows that implementing PIU is a viable way to improve medical services in Saudi Arabia. Despite initial successes, sustainability is still lacking, which highlights the need to improve further the participation, motivation and training of team leaders and members to make the program a long-term success.

2) Duration: How many hours of contact time and how long?

3) Collective participation: To what extent are participants currently cooperating with teachers in the same school, grade or department?

4) Inclusiveness: Whether to invite all teachers in a particular community to participate?

5) Motivation: Does the teacher have a reasonably active motivation to participate?

6) Positive learning opportunities: Do teachers engage in meaningful and relevant activities?

7) Content focus: Do you focus on the classroom exercises of the teacher and the learning style of the students?

8) Coherence: Does the plan meet standards or teacher goals? 


\subsubsection{Retaining Professionals}

The retention rate is the percentage of employees retained in the organization. In contrast, the turnover rate is the opposite of the retention rate, which explains the percentage of employees who leave the organization for some reason. Retaining human resource practices for professional employees with valuable skills will be a priority. When done successfully, it can reduce organization turnover. To minimize the turnover of valuable people, organizations have considered human resource practices to increase employee job satisfaction and organizational commitment. In particular, organizations benefit from providing personal and professional development, feedback on performance, and appropriate rewards. These improved attitudes prevent employee outflows. Another structure that has recently attracted academic attention in preventing churn is job embedding, a retention (or "anti-draw") structure. It increases predictions of turnover rates and goes beyond attitudes such as job satisfaction and commitment while focusing on why people stay. Specifically, the embeddedness of work inside and outside of work is focused on social connections (links), value correspondence between individuals, organizations, and the environment (adaptation) and benefits that individuals need to give up when they leave (sacrifice).

\section{Methodology}

This paper is a critical review of the existing literature taken from different sources like government documents, databases, articles, reports, books, and related previous researches. The paper is an attempt to identify the challenges confronting the delivery of training and development programs and to evaluate the effectiveness of such training and development activities in the Saudi Arabian context. Moreover, the study is inclined to review the challenges faced by the managers/trainers in transferring knowledge and skills in the Saudi workforce to ensure that they can effectively contribute in the future success of their country. Lastly, the study reviews different training programs initiated on entrepreneurial education in Saudi Arabian context.

We decided to conduct a qualitative review of the literature rather than a meta-analysis, based on several factors. Research on the beneficial effects of training and development interventions is still in its infancy. Before it is appropriate to aggregate basic research and draw firm conclusions about the scale of population impact, there are many definitions, concepts, and measurement issues that need to be addressed (Sutcliffe, Vogus, \& Dane, 2016; Jamieson \& Tuckey, 2017). Besides, quantitative reviews will require careful consideration of study design characteristics. First, combining studies that use random groupings with studies that do not use random groupings can artificially increase the effect size estimates (O'Connor et al., 2008). The second challenge involves the use of the evaluation design to conduct a summary study when the comparison target is different (for example, the pre-test/post-test design of a single group compares the same person over time, and the pre-test/post-test design is compared to a control group). The intervention of different factors has an unexplained degree of impact. 
In assessing the feasibility of conducting a meta-analysis review, we found that the number of basic studies using a specific type of evaluation design and checking for common results was very small ( $92 \%$ of basic studies had five or fewer). This little knowledge prevents the researcher from checking potentially important hosts such as training time or course content. Based on these considerations, we have conducted an in-depth qualitative review of the literature to lay the foundation for future meta-analysis work. To this end, we have established a training research framework based on the classification of various training design and delivery functions, and qualitatively summarised the types of inspection results in Saudi Arabia.

\section{Literature Search and Inclusion Criteria}

A two-step search procedure was used to ensure a systematic search for both older and more recently published articles. Relevant empirical research is extracted in a variety of ways based on the suggestions of Macpherson and Jones (2010) and Denyer and Tranfield (2009). First, literature searches were performed in "Science Direct", "PsycINFO", "Emerald", and "ProQuest Thesis and Dissertation" (1995-2020), It included published and unpublished studies to reduce publication bias possibility. Search terms used where training and development, training methods, training delivery, training transfer, training effect and development, capacity building, training design effect, and entrepreneurial education. Google Scholar was also searched using the same keywords, and methods were added (e.g., training and methods, training results). Secondly, a reference list derived from a previous meta-analysis of related topics conducted a cross-check, and the initial search returned 11,244 articles. According to the Statistics Portal (2020), Figure 1 shown the training and development publishing distribution between 1995 to 2020 :

We included case studies, longitudinal researches, review of the literature and descriptive studies that discuss the training and development in different countries. We preferred articles published in English based on a sample of adults (excluded studies of children or adults with a medical condition). Each study was reviewed and included if the following conditions were met:

- Aims/objectives of the study are clearly stated

- It included an empirical evaluation of training and development, capacity building, training design program effectiveness and entrepreneurial education

- The data collection method is described clearly

- The study used a repeated measures design, independent groups design, or an independent groups design with repeated measures

- Sampling and calculation of sample size are described

- Measures in place to ensure that results are valid and reliable

- Mention of any assumptions made

- Ethics: For a study to be included in the review, it had to either report or allow the computation of a correlation coefficient between any of the predictor 
variables and a measure of training transfer.

The results of this search strategy can be found in Figure 2. The study excluded more than 5000 articles, as the papers were either related to the specified context. This left 295 articles for full-text review. A further 188 articles were excluded because they were not relevant to the topic or were opinion articles, letters, editorials, or reports. One hundred and nine articles were identified as relevant. Four additional relevant studies were identified after hand-searching of the references of these studies. One hundred and twenty-nine articles were, therefore, finally relevant and are included in this systematic review (Figure 2, Table 3).

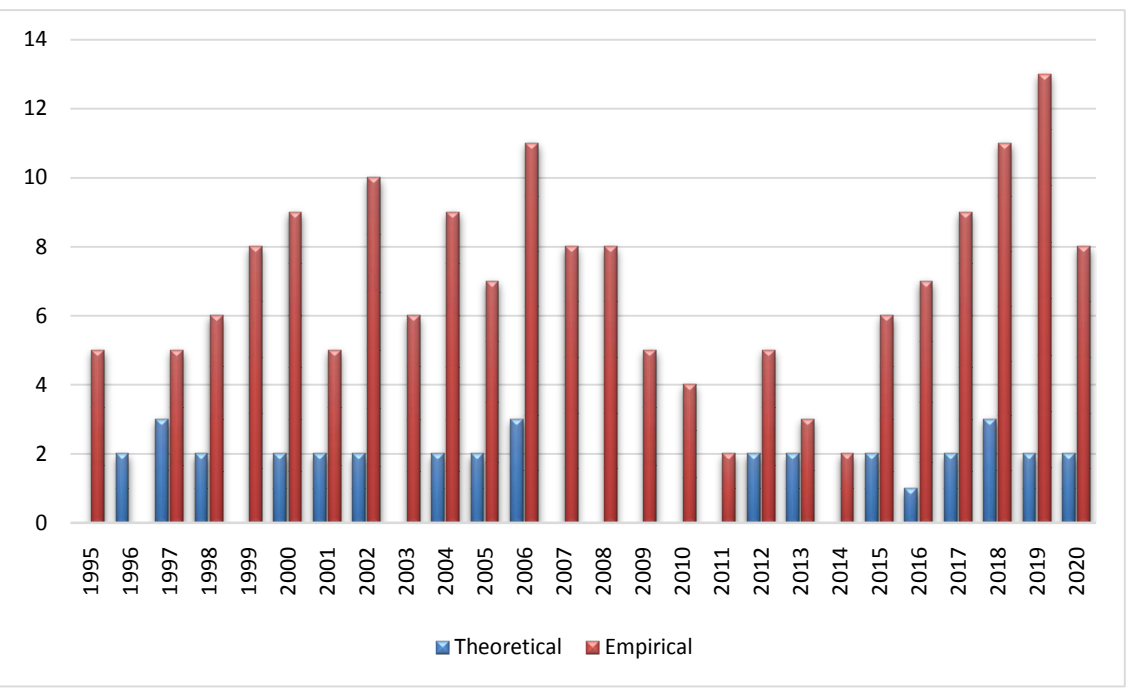

Figure 1. Training and development Publication Distribution.

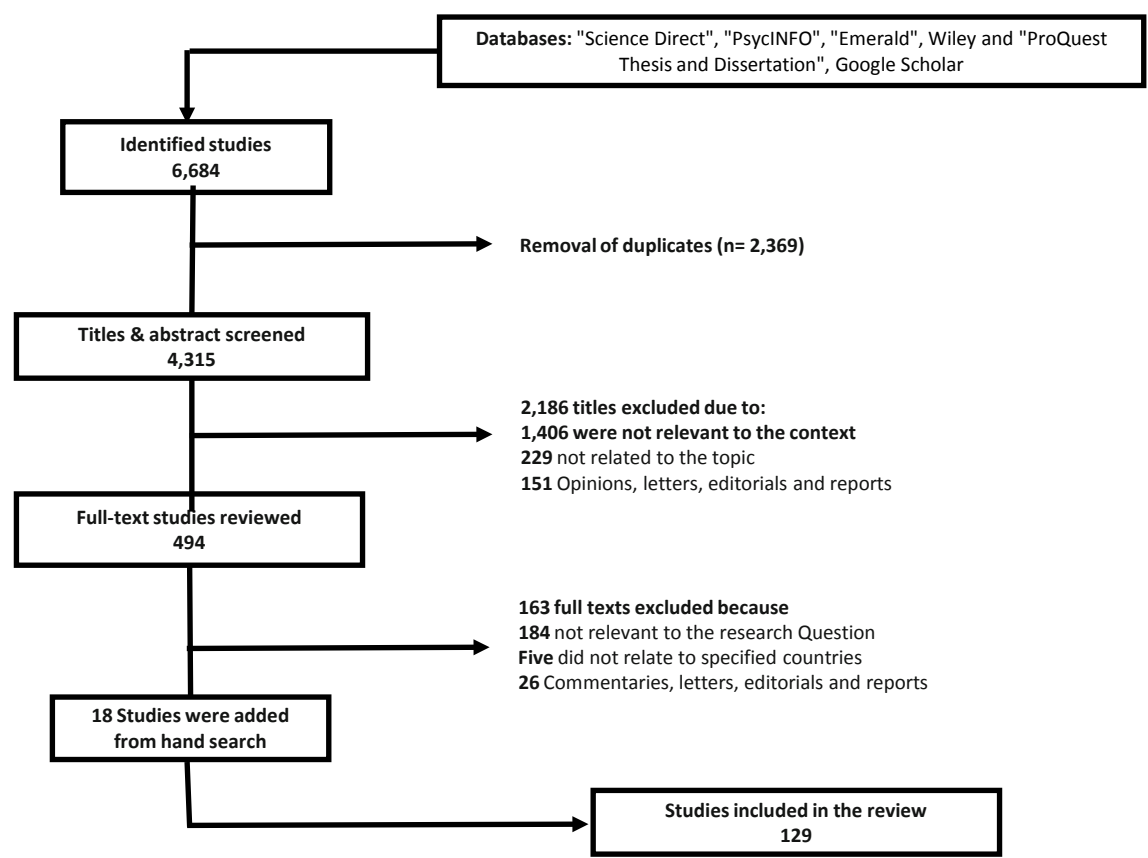

Figure 2. Flow chart for the search and review process. 
Table 3. Detail of Journals used in the review of literature.

\begin{tabular}{|c|c|c|}
\hline \multicolumn{3}{|l|}{ Training and Development Journals } \\
\hline Journal Title & Article Count & $\%$ \\
\hline \multicolumn{3}{|l|}{ Training and Development Journals } \\
\hline The International Journal of Training and Development & 15 & $12 \%$ \\
\hline International Journal of Training Research & 8 & $6 \%$ \\
\hline Journal of European Industrial Training & 12 & $9 \%$ \\
\hline European Journal of Training and Development (formally Journal of European Industrial Training) & 13 & $10 \%$ \\
\hline \multicolumn{3}{|l|}{ Human Resource Development Journals } \\
\hline Journal of Workplace Learning & 4 & $3 \%$ \\
\hline Human Resource Development Quarterly & 2 & $2 \%$ \\
\hline Human Resource Management Review & 1 & $1 \%$ \\
\hline Journal of Vocational Education and Training & 1 & $1 \%$ \\
\hline Education and Training & 10 & $8 \%$ \\
\hline Human Resource Development International Journal of Education and Work & 9 & $7 \%$ \\
\hline Learning Organization & 1 & $1 \%$ \\
\hline Career Development International & 1 & $1 \%$ \\
\hline Journal of Management Development & 1 & $1 \%$ \\
\hline Advances in Developing Human Resources & 1 & $1 \%$ \\
\hline \multicolumn{3}{|l|}{ Human Resource Management Journals } \\
\hline International Journal of Human Resource Management & 4 & $3 \%$ \\
\hline New Technology, Work and Employment & 1 & $1 \%$ \\
\hline Employee Relations & 2 & $2 \%$ \\
\hline International Journal of Manpower & 1 & $1 \%$ \\
\hline Human Resource Management Journal & 3 & $2 \%$ \\
\hline Personnel Review & 3 & $2 \%$ \\
\hline Asia Pacific Journal of Human Resources & 1 & $1 \%$ \\
\hline \multicolumn{3}{|l|}{ Strategic Management/ General Management//Organizational Studies Journals } \\
\hline Human Relations & 1 & $1 \%$ \\
\hline International Journal of Management & 1 & $1 \%$ \\
\hline Strategic Change & 2 & $2 \%$ \\
\hline Work Employment and Society & 2 & $2 \%$ \\
\hline International Journal of Management Reviews & 1 & $1 \%$ \\
\hline \multicolumn{3}{|l|}{ SME and Entrepreneurship Journals } \\
\hline International Journal of Entrepreneurial Behaviour and Research & 1 & $1 \%$ \\
\hline Journal of Small Business Management & 3 & $2 \%$ \\
\hline Entrepreneurship Theory and Practice & 1 & $1 \%$ \\
\hline International Entrepreneurship and Management Journal & 1 & $1 \%$ \\
\hline International Journal of Entrepreneurship and Innovation & 3 & $2 \%$ \\
\hline International Small Business Journal & 6 & $5 \%$ \\
\hline Journal of Small Business and Enterprise Development & 9 & $7 \%$ \\
\hline Total & 129 & \\
\hline
\end{tabular}




\section{Analysis}

\subsection{Coding Process Overview}

Coding staff were trained to do coding and reading of the training and development research. From each research, the information on the author, publication year, research country, sector, profession, research design, sample size, characteristics of the control group, time frame, targeted results, or outcomes, training plan, time of training, number of people, training course time, training delivery methods and outcomes were collected. Throughout the coding process, group discussions were used to clarify decision rules, solve coding problems, and regulate the process of coding.

The study was coded into two stages. In the first stage of studies, there were 57 studies included in previous "bare-bones" reviews. These studies were coded by research team members and then individually by researchers, and then checked by senior authors. In the second stage of coding, the search was expanded to systematically identify all previously published studies that examined employees' mindfulness interventions. This will determine the type of target results and the percentage of studies that include each target result. In the second stage of coding, the original 57 studies were coded a second time, and more information was captured.

\subsection{Study Design Features}

Several methodological characteristics of training and development interventions are documented. The specific coded characteristics include the study design (for example, pre-test/post-test no control group), control group characteristics (presence or absence; in case of present an active member or active member), and schedule of evaluation (for example, number of follow-ups after training; follow-up time).

\subsection{Characteristics of Training Content}

Training contents is the element often referred to as tools or methods used for training. To provide a fine-grained understanding, the study reviewed different training contents including course management system, books, literature and technological educational tools, appropriate pedagogies, e.g. offline and online discussions, seminars and workshops, instructional designs and models, problem-solving learning, experiential learning, blended training, meditation-based training and training duration (total training sessions, time and duration).

\subsection{Training Deliver}

We recorded information on all training delivery methods (e.g. lectures, guided exercises, recordings) described in each study. The study is then coded for lectures, recordings, group discussions, written materials, retreats, and online modules. We also coded two exercise characteristics; whether there was an opportunity to perform the exercise, and whether the type of exercise was recorded as part of the training intervention (for example, only doing homework in meetings). 


\subsection{Target Result}

We recorded the names of all dependent variables for each measurement in the 129 studies, and then classify them into a broader but conceptually uniform result category (Hycner, 1985). These broad outcome categories are used to determine the intended purpose of training interventions, and to compare the relative frequency of training for different outcome types. In some studies, a single outcome category (e.g., self-regulation) has multiple operations (e.g., surface actions, emotional regulation). For the previous example, studies that measure both surface behaviour and emotional regulation (both under the broader self-regulation goal outcome) will count once in the self-regulation goal outcome category.

\section{Discussion and Findings}

Table 4 below shows the use of different training modes in previous literature. The results depict that $94 \%$ of training uses lecture method, $59 \%$ use some audio-visual recordings, $52 \%$ use group discussions, $38 \%$ use printed materials, $17 \%$ use retreats, and $7 \%$ use online modules.

Similarly, training outcomes are observed in the following proportionate given in Table 5 below. Mostly the training is considered to be a good source of stress reduction, mindfulness, wellbeing, compassion, self-regulation, affect, healthy behaviours, commitment, performance, job satisfaction and motivation experience.

The study aims to conduct a detailed qualitative literature review on training and development interventions in the context of Saudi Arabia. Based on our findings, some general conclusions can be drawn. First, there is growing attention in training and development in the kingdom. Seventy-five per cent of the included studies were published between 2012 and the end of February 2020. Second, about two-thirds of the evaluation designs used in the study included some type of control groups. This may lead to more robust inferences about the effects of interventions (Cook et al., 1979) and carries a knowledge base in the field.

Table 4. Training details.

\begin{tabular}{|c|c|c|c|}
\hline Mode of delivery & Details & $\mathrm{N}$ & $\%$ \\
\hline Lecture method & Educational instruction and guide by some expert in the relevant area & 66 & $94 \%$ \\
\hline Audial recording & Recorded sound or audio facts and details like video clips and guided meditation. & 40 & $59 \%$ \\
\hline Group discussions & $\begin{array}{l}\text { Activities completed by the entire training group or in smaller groups. Includes sharing } \\
\text { of personal experiences, debriefing on in-class exercises, and giving-receiving feedback. }\end{array}$ & 35 & $52 \%$ \\
\hline Printed materials & Includes hand-outs, worksheets, written exercises, diaries, etc. & 27 & $38 \%$ \\
\hline Retreat & $\begin{array}{l}\text { Group off-site experiential activity. May include silent meditation, walking meditation, } \\
\text { or other activities. }\end{array}$ & 13 & $17 \%$ \\
\hline Online modules & $\begin{array}{l}\text { Whole or part of the training offered via the internet or other form of distance-learning } \\
\text { such as telephone (e.g., coaching). }\end{array}$ & 5 & $7 \%$ \\
\hline
\end{tabular}

1. Attention. Based on $\mathrm{N}=129$ studies. The total percentages are more than $100 \%$ because many studies have added different means of delivery. 
Table 5. Outcomes of training.

\begin{tabular}{|c|c|c|c|}
\hline Outcomes of Training & Conceptualization of concept & $\mathbf{N}$ & $\%$ \\
\hline Job Stress & $\begin{array}{l}\text { A Person's emotional, physical, mental strain perceptions, arises when in a particular job situation } \\
\text { compels him to demand more than his social and personal resources, he owns to fulfils the demand. }\end{array}$ & 54 & $81 \%$ \\
\hline Mindfulness & Involves positive assessments of an individual's circumstances and life; & 39 & $58 \%$ \\
\hline Wellbeing & $\begin{array}{l}\text { Involves the perceptions about felt happiness or pleasure; individual's growth perceptions; self-efficacy, } \\
\text { legitimacy, and the quest of life meaning; the existence of psychological properties. }\end{array}$ & 23 & $34 \%$ \\
\hline Compassion & Perception of empathy and sympathy concerning to individual himself and other counterparts. & 18 & $27 \%$ \\
\hline Self-regulation & $\begin{array}{l}\text { The voluntary response of development of based on an individual's goal-directedness sense and } \\
\text { feedback reliance that guide s him to alter his behaviour }\end{array}$ & 11 & $16 \%$ \\
\hline Affect & $\begin{array}{l}\text { Perceptual experience or emotional state of mind showing his present state relative to his environment. } \\
\text { Like an individual's general feeling are not related to a specific item or incident (e.g. moods) as well as } \\
\text { affective responses related to a particular event or experience (e.g. emotions). }\end{array}$ & 10 & $15 \%$ \\
\hline Health behaviours & The important behaviours that support the health of the individual & 10 & $15 \%$ \\
\hline Commitment & A cognitive state of dedication toward some object or goal or organization & 8 & $12 \%$ \\
\hline Performance & $\begin{array}{l}\text { No. of tasks performed and their quality at the workplace or development of skills essential for higher } \\
\text { performance. }\end{array}$ & 8 & $12 \%$ \\
\hline Job satisfaction & $\begin{array}{l}\text { Emotional responses and job task related perceptions, relationships on the job, or other environmental } \\
\text { characteristics. }\end{array}$ & 6 & $9 \%$ \\
\hline Motivation & A drive to fulfil personal desires or a reason for a particular behaviour & 6 & $9 \%$ \\
\hline $\begin{array}{l}\text { Expectancies or } \\
\text { outcomes }\end{array}$ & A belief for something positive will happen or the particular results of some event & 5 & $8 \%$ \\
\hline $\begin{array}{l}\text { Self-support/sense } \\
\text { of achievement }\end{array}$ & $\begin{array}{l}\text { Meeting self's requirement with self-effort or proud feeling for gaining something impossible or } \\
\text { difficult }\end{array}$ & 4 & $6 \%$ \\
\hline Engagement & $\begin{array}{l}\text { An individual's extent of investment in emotional, physical and cognitive willingness to perform the } \\
\text { assigned role. }\end{array}$ & 3 & $5 \%$ \\
\hline
\end{tabular}

1. Type of target results and percentage of study, including each target result. 2. Attention. Based on $\mathrm{N}=129$ studies. The total percentages are more than $100 \%$ because many studies have added different categories of results more than one.

Third, this review also revealed significant differences in the contents of training programmes, training delivery methods, variable practices of countries, total training time, length and number of training sessions. Fourth, although the most common goal of training and development is to reduce stress, plans often have other intended purposes.

\section{Integration with Existing Training Models and Theories of Training Effectiveness}

\section{Training Content}

Our review indicates that various training programs are being used to decide training contents particularly the methods like course management system, books, literature and technological educational tools (like blogs, Wikipedia), appropriate pedagogies and more. As organizations are interested in broader outcomes, including job satisfaction, performance, and employee engagement, we may find that other training content may be necessary. For example, training may be particularly useful for enhancing safety, engagement, or job performance. 


\section{Training Delivery}

The research found that most of the training programs use multiple methods to deliver the training content. A similar conclusion was drawn by the meta-analysis of Arthur, Bennett, Edens, \& Bell (2003) on training effectiveness in the workplace. It is worth noting that lectures are used in almost all types of training across countries. Despite the prevalent belief that the lecture method is uninteresting and boring the previous researches admitted that it plays a vital role in training and development. For instance, Arthur et al. (2003) reported that the lecture-based training alone or in combination with other approaches generally offers required outcomes both for learnt skills and assessment criteria. So, the results are encouraging because this method might help understand various vital aspects of organizational performance as well as the individual's own life at work. Training also offers deliberate planning covering the how, when, and where the firm aims to invest in human capital (Sitzmann \& Johnson, 2012).

\section{The Intended Purpose of Training, Targeted Industries and Occupations} The studies reviewed in this paper have highlighted multiple outcomes of training and development, as shown in Table 5. This study is essential in the Saudi Arabian context because the government, under its Vision 2030, wants to improve the quality of its human resource. Numerous factors, like peers, supervisors, and organizations, can positively participate in enhancing the effectiveness of training delivery at work. Several hurdles like excessive workload and less potential for skill utilization at organizational as well as individual-level prevails and influences the quality of training outcomes further the organizational culture and climate might lessen the chances of individual engagement in training (Salas, Weaver, \& Shuffler, 2012; Brown \& Sitzmann, 2011). The literature also shows that many characteristics of the trainer, such as self-efficacy and pre-training, lead to the successful transfer of training (Thayer \& Teachout, 1995). Therefore, the study advises that introducing training as a source of skills improvement for all the workers, even those who have no prior work experience can potentially increase the motivation to get training and also its effective transfer.

\section{Conclusion}

To sum up, this study is essential in the Saudi Arabian context because the government, under its Vision 2030, wants to improve the quality of its human resource. Numerous factors, like peers, supervisors, and organizations, can positively participate in enhancing the effectiveness of training delivery at work. Several hurdles like excessive workload and less potential for skill utilization at organizational as well as individual-level prevails and influences the quality of training outcomes further the organizational culture and climate might lessen the chances of individual engagement in training. The literature also shows that many characteristics of the trainer, such as self-efficacy and pre-training, lead to the successful transfer of training. Therefore, the study advises that introducing 
training as a source of skills improvement for all the workers, even those who have no prior work experience can potentially increase the motivation to get training and also its effective transfer. This study explored the delivery of training and development programs from multiple stakeholder perspectives to identify best practices for training delivery by identifying consistent and emerging factors in the literature. The results show that trainers have the opportunity to consider how they can increase their knowledge of transfer factors and play a more significant role in supporting delivery in part of the organization's training and development plan. As organizations continue to invest in training to improve performance, migration remains a challenge for training professionals. Although training is often criticized for not having a significant impact, many still believe that if properly managed, it can influence and support performance improvement at the individual, team, and organizational levels. Training delivery is an essential step between training and performance improvement, and it will remain a critical factor in determining the success of a training program. The limitation of this study is that it does not produce enough cases to sustain the types proposed or further studied for the second and third phases. That shown an opportunity for future research to increases the number of studies for the second and third phases. Moreover, researchers recommended to investigate these challenges in a different context and compare the result with this paper. As well as find solutions to these challenges, which could help the government and decision-maker to overcome these challenges.

\section{Conflicts of Interest}

The authors declare no conflicts of interest regarding the publication of this paper.

\section{References}

Achoui, M. M. (2009). Human Resource Development in Gulf Countries: An Analysis of the Trends and Challenges Facing Saudi Arabia. Human Resource Development International, 12, 35-46. https://doi.org/10.1080/13678860802638826

Ahmad, T., Farrukh, F., \& Nazir, S. (2019). Capacity Building Boost Employees Performance. Industrial and Commercial Training, 47, 61-66. https://doi.org/10.1108/ICT-05-2014-0036

Airhihenbuwa, C. O., Ogedegbe, G., Iwelunmor, J., Jean-Louis, G., Williams, N., Zizi, F., \& Okuyemi, K. (2015). Claim Your Space: Leadership Development as a Research Capacity Building Goal in Global Health. Health Education and Behavior, 43, 17S-24S. https://doi.org/10.1177/1090198116633455

Al-Hanawi, M. K., Khan, S. A., \& Al-Borie, H. M. (2019). Healthcare Human Resource Development in Saudi Arabia: Emerging Challenges and Opportunities-A Critical Review. Public Health Reviews, 40, Article No. 1. https://doi.org/10.1186/s40985-019-0112-4

Alvarez, K., Salas, E., \& Garofano, C. M. (2004). An Integrated Model of Training Evaluation and Effectiveness. Human Resource Development Review, 3, 385-416. https://doi.org/10.1177/1534484304270820 
Arthur Jr., W., Bennett Jr, W., Edens, P. S., \& Bell, S. T. (2003). Effectiveness of Training in Organizations: A Meta-Analysis of Design and Evaluation Features. Journal of Applied Psychology, 88, 234. https://doi.org/10.1037/0021-9010.88.2.234

Arthur, M., Butterfield, N., \& McKinnon, D. H. (1998). Communication Intervention for Students with Severe Disability: Results of a Partner Training Program. International Journal of Disability, Development and Education, 45, 97-115.

Baldwin, T., \& Ford, J. K. (1988). Transfer of Training: A Review and Directions for Future Research Problem Solving View Project MSU Primary Care Faculty Development Fellowship View Project. Personnel Psychology, 41, 63-105. https://doi.org/10.1111/j.1744-6570.1988.tb00632.x

Barber, A. E., Wesson, M. J., Roberson, Q. M., \& Taylor, M. S. (1999). A Tale of Two Job Markets: Organizational Size and Its Effects on Hiring Practices and Job Search Behaviour. Personnel Psychology, 52, 841-868. https://doi.org/10.1111/j.1744-6570.1999.tb00182.x

Bartlett, K. R., \& Kang, D. S. (2004). Training and Organizational Commitment among Nurses Following Industry and Organizational Change in New Zealand and the United States. Human Resource Development International, 7, 423-440. https://doi.org/10.1080/1367886042000299799

Bates, A. W., \& Poole, G. (2005). Effective Teaching with Technology in Higher Education: Foundations for Success (Vol. 19).

Baum, T. (2007). Human Resources in Tourism: Still Waiting for Change Is There a Future for Low Skills Service Work? View Project Human Resources in Tourism: Still Waiting for Change. Tourism Management, 28, 1383-1399.

https://doi.org/10.1016/j.tourman.2007.04.005

Beardwell, J., \& Claydon, T. (2010). Human Resource Management: A Contemporary Approach. https://lib.ugent.be/catalog/rug01:002070678

Becker, G. S. (1962). Investment in Human Capital: A Theoretical Analysis. Journal of Political Economy, 70, 9-49. https://doi.org/10.1086/258724

Bell, B. S., \& Kozlowski, S. W. J. (2008). Active Learning: Effects of Core Training Design Elements on Self-Regulatory Processes, Learning, and Adaptability. Journal of Applied Psychology, 93, 296-316. https://doi.org/10.1037/0021-9010.93.2.296

Berry, M. L., \& Morris, M. L. (2005). Organizational Factors Impacting Sexual Harassment Prevention Programs. In Proceedings of the 2005 Academy of Human Resource Development Annual Conference (pp. 1271-1278). Estes Park, CO: Academy of HRD.

Brinkerhoff, D. W. (2010). Developing Capacity in Fragile States. Public Administration and Development, 30, 66-78. https://doi.org/10.1002/pad.545

Brinkerhoff, D. W., \& Peter Morgan, W. J. (2014). Capacity and Capacity Development: Coping with Complexity. Public Administration and Development, 30, 2-10. https://doi.org/10.1002/pad.559

Brown, K. G., \& Sitzmann, T. (2011). Training and Employee Development for Improved Performance. In APA Handbook of Industrial and Organizational Psychology, Vol. 2: Selecting and Developing Members for the Organization (pp. 469-503). Washington DC: American Psychological Association. https://doi.org/10.1037/12170-016

Buqawa, A., Al-Jayyousi, O., Alsultanny, Y., Bhandari, M., Bugawa, A. M., Al-Jayyousi, O. R., Alsultanny, Y. A., Bhandari, M. P., \& Mirzal, A. (2018). An Overview on Professional Education Development in Technology Management: The Experience of Arabian Gulf University. The Asia-Pacific Journal of Educational Management Research, 3, 39-48. https://doi.org/10.21742/ajemr.2018.3.1.07 
Burke, L. A., \& Baldwin, T. T. (1999). Workforce Training Transfer: A Study of the Effect of Relapse Prevention Training and Transfer Climate. Human Resource Management, 38, 227-242. https://doi.org/10.1002/(SICI)1099-050X(199923)38:3<227::AID-HRM5>3.0.CO;2-M

Burke, L. A., \& Hutchins, H. M. (2007). Training Transfer: An Integrative Literature Review. Human Resource Development Review, 6, 263-296.

https://doi.org/10.1177/1534484307303035

Clare, J., \& Hawes, C. (2001). Engendering Change: Empowering Nurse Academics to Take Part in a University Research Culture. The Australian Journal of Advanced Nursing: A Quarterly Publication of the Royal Australian Nursing Federation, 18, 32-36.

Cook, P. (1998). The Creativity Advantage-Is Your Organization, the Leader of the Pack? Industrial and Commercial Training, 30, 179-184. https://doi.org/10.1108/00197859810225652

Cook, T. D., Campbell, D. T., \& Day, A. (1979). Quasi-Experimentation: Design \& Analysis Issues for Field Settings (Vol. 351). Boston: Houghton Mifflin.

Crookes, P. A., \& Bradshaw, P. L. (2002). Developing Scholarship in Nursing-Steps within a Strategy. Journal of Nursing Management, 10, 177-181.

https://doi.org/10.1046/j.1365-2834.2002.00326.x

Crossley, M. (2019). Policy Transfer, Sustainable Development and the Contexts of Education. Compare, 49, 175-191. https://doi.org/10.1080/03057925.2018.1558811

Denyer, D., \& Tranfield, D. (2009). Producing a Systematic Review. In D. A. Buchanan, \& A. Bryman (Eds.), The Sage Handbook of Organizational Research Methods (pp. 671-689). New York: Sage Publications Ltd.

Driskell, J. E., Willis, R. P., \& Copper, C. (1992). Effect of Overlearning on Retention. Journal of Applied Psychology, 77, 615-622. https://doi.org/10.1037/0021-9010.77.5.615

Drost, E. A., Frayne, C. A., Lowe, K. B., \& Michael Geringer, J. (2002). Benchmarking Training and Development Practices: A Multi-Country Comparative Analysis. Human Resource Management, 41, 67-86. https://doi.org/10.1002/hrm.10020

Farrington, A. (1996). Developing a Research Culture for Nursing in Higher Education. British Journal of Nursing (Mark Allen Publishing), 5, 57-58. https://doi.org/10.12968/bjon.1996.5.1.57

Feldman, H. R., \& Acord, L. (2002). Strategies for Building Faculty Research Programs in Institutions That Are Not Research-Intensive. Journal of Professional Nursing, 18, 140-146. https://doi.org/10.1053/jpnu.2002.124486

Flippo, E. B. (1979). A Talk with Professor Flippo. Asia Pacific Journal of Human Resources, 17, 32-40. https://doi.org/10.1177/103841117901700205

Fussy, D. S. (2019). The Hurdles to Fostering Research in Tanzanian Universities. Higher Education, 77, 283-299. https://doi.org/10.1007/s10734-018-0276-8

Galvão, A. R., Marques, C. S. E., Ferreira, J. J., \& Braga, V. (2020). Stakeholders' Role in Entrepreneurship Education and Training Programmes with Impacts on Regional Development. Journal of Rural Studies, 74, 169-179.

https://doi.org/10.1016/j.jrurstud.2020.01.013

Georgenson, D. L. (1982). The Problem of Transfer Calls for Partnership. Training \& Development Journal, 36, 75. https://psycnet.apa.org/record/1983-04546-001

Gething, L., \& Leelarthaepin, B. (2000). Strategies for Promoting Research Participation among Nurses Employed as Academics in the University Sector. Nurse Education Today, 20, 147-154. https://doi.org/10.1054/nedt.1999.0382 
Gist, M. E., Schwoerer, C., \& Rosen, B. (1989). Effects of Alternative Training Methods on Self-Efficacy and Performance in Computer Software Training. Journal of Applied Psychology, 74, 884-891. https://doi.org/10.1037/0021-9010.74.6.884

GOTEVOT (1994). Technical Education and Vocational Training: the Past and the Present (4th ed.). Riyadh: Public Relations, GOTEVOT.

Govender, I. G. (2016). Monitoring and Evaluation Capacity Development of Municipalities in the Province of KwaZulu-Natal, South Africa. Journal of Human Ecology, 56, 263-271. https://doi.org/10.1080/09709274.2016.11907063

Grossman, R., \& Salas, E. (2011). The Transfer of Training: What Really Matters. International Journal of Training and Development, 15, 103-120. https://doi.org/10.1111/j.1468-2419.2011.00373.x

Hassanain, M. (2017). An Overview of the Performance Improvement Initiatives by the Ministry of Health in the Kingdom of Saudi Arabia. Inquiry (United States), 54. https://doi.org/10.1177/0046958017707872

Heimbeck, D., Frese, M., Sonnentag, S., \& Keith, N. (2003). Integrating Errors into the Training Process: The Function of Error Management Instructions and the Role of Goal Orientation. Personnel Psychology, 56, 333-361.

https://doi.org/10.1111/j.1744-6570.2003.tb00153.x

Hill, Y. V., Lomas, L., \& Macgregor, J. (2003). Managers, Researchers, Teachers and Dabblers: Enabling a Research Culture in Nursing Departments in Higher Education Institutions. Journal of Further and Higher Education, 27, 317-331.

https://doi.org/10.1080/0309877032000098725

Holton III, E. F., Baldwin, T. T., \& Naquin, S. S. (2000). Managing and Changing Learning Transfer Systems. Advances in Developing Human Resources, 8, 23-35.

Holton, E. (1996). Academy of Human Resource Development: 1996 Conference Proceedings.

Holton, E. F. (2005). Holton's Evaluation Model: New Evidence and Construct Elaborations. Advances in Developing Human Resources, 7, 37-54. https://doi.org/10.1177/1523422304272080

Holton, E. F., Bates, R. A., \& Ruona, W. E. A. (2000). Development of a Generalized Learning Transfer System Inventory. Human Resource Development Quarterly, 11, 333-360. https://doi.org/10.1002/1532-1096(200024)11:4<333::AID-HRDQ2>3.0.CO;2-P

Hornsby, J. S., \& Kuratko, D. F. (1990). Human Resource Management in Small Business: Critical Issues for the 1990s. Journal of Small Business Management, 28, 9.

Horton, S. (2000). Competency Management in the British Civil Service. International Journal of Public Sector Management, 13, 354-368. https://doi.org/10.1108/09513550010350508

Huselid, M., Becker, B., Ulrich, D., Becker, B., \& Ulrich, D. (2001). The HR Scorecard: Linking People, Strategy, and Performance. Boston, MA: Harvard Business School Press.

Hycner, R. H. (1985). Some Guidelines for the Phenomenological Analysis of Interview Data. Human Studies, 8, 279-303. https://doi.org/10.1007/BF00142995

Iredale, R., \& Cleverly, A. (1998). Education and Training in Genetics in Social Work Programmes across the United Kingdom. British Journal of Social Work, 28, 961-968. https://doi.org/10.1093/oxfordjournals.bjsw.a011410

Jamieson, S. D., \& Tuckey, M. R. (2017). Mindfulness Interventions in the Workplace: A Critique of the Current State of the Literature. Journal of Occupational Health Psychology, 22, 180. https://doi.org/10.1037/ocp0000048 
Kaplan, A. (2000). Capacity Building: Shifting the Paradigms of Practice. Development in Practice, 10, 517-526. https://doi.org/10.1080/09614520050116677

Keith, N., \& Frese, M. (2008). Effectiveness of Error Management Training: A Meta-Analysis. Journal of Applied Psychology, 93, 59-69.

https://doi.org/10.1037/0021-9010.93.1.59

KPMG (2019). The Future of H.R. 2019: Key Findings.

https://www.google.com/url?sa=t\&rct=j\&q=\&esrc=s\&source=web\&cd=2\&ved=2ahUKE wiY3LP2qdPnAhWPMBQKHUTKBsMQFjABegQIAxAB\&url=https\%3A\%2F\%2Fadviso ry.kpmg.us\%2Fcontent\%2Fdam\%2Fadvisory\%2Fen\%2Fpdfs\%2Fhr-survey-2019-key-fin dings.pdf\&usg=AOvVaw0U2yOiQ6AYBnwRepsus9fh

Kraiger, K. (2003). Perspectives on Training and Development. Handbook of Psychology (pp. 171-192). Hoboken, NJ: John Wiley \& Sons, Inc. https://doi.org/10.1002/0471264385.wei1208

Kraiger, K., \& Ford, J. K. (2014). The Expanding Role of Workplace Training: Themes and Trends, Influencing Training Research and Practice. In Historical Perspectives in Industrial and Organizational Psychology (pp. 281-309). New York: Psychology Press.

Kupritz, V. W. (2002). The Relative Impact of Workplace Design on Training Transfer. Human Resource Development Quarterly, 13, 427-447. https://doi.org/10.1002/hrdq.1042

Lavergne, R., \& Saxby, J. (2001). Capacity Development: Vision and Implication (pp. 1-11). Capacity Development Occasional Series, Vol. 6088, Canadian International Development Agency.

Lim, D. H., \& Morris, M. L. (2006). Influence of Trainee Characteristics, Instructional Satisfaction, and Organizational Climate on Perceived Learning and Training Transfer. Human Resource Development Quarterly, 17, 85-115. https://doi.org/10.1002/hrdq.1162

Linnel, D. (2003). Evaluation of Capacity Building: Lessons from the Field. Bulletin of the World Health Organization, 83, 263-271.

Lusthaus, C., Adrien, M., \& Perstinger, M. (1999). Capacity Development: Definitions, Issues and Implications for Planning, Monitoring and Evaluation. Development, 35, 1-21.

Macpherson, A., \& Jones, O. (2010). Editorial: Strategies for the Development of International Journal of Management Reviews. International Journal of Management Reviews, 12, 107-113. https://doi.org/10.1111/j.1468-2370.2010.00282.x

Martins, T., Midão, L., Martínez Veiga, S., Dequech, L., Busse, G., Bertram, M., McDonald, A., Gilliland, G., Orte, C., Vives, M., \& Costa, E. (2019). Intergenerational Programs Review: Study Design and Characteristics of Intervention, Outcomes, and Effectiveness: Research. Journal of Intergenerational Relationships, 17, 93-109. https://doi.org/10.1080/15350770.2018.1500333

Matachi, A. (2006). Capacity Building Framework. UNESCO-IICBA UNESCO International Institute for Capacity Building in Africa. cvhpc.org. http://www.cvhpc.org/wp-content/uploads/Capacity-Building-Framework.pdf

Matthew Amlôt, A. A. E. (2019). Saudi Arabia Announces New Electricity Tariffs-AI Arabiya English.

http://english.alarabiya.net/en/business/economy/2019/12/09/Saudi-Arabia-announces -272-billion-2020-budget.html

McCreaddie, M., Kuzemski, D., Griffiths, J., Sojka, E. M., Fielding, M., Al Yateem, N., \& Williams, J. J. (2018). Developing Nursing Research in the United Arab Emirates: A Narrative Review. International Nursing Review, 65, 93-101.

https://doi.org/10.1111/inr.12405 
Mullins, L. J., \& Christy, G. (2010). Individual Differences and Diversity. In L. J. Mullins (Ed.), Organizational Behavior (9th ed). Upper Saddle River, NJ: Pearson Prentice Hall.

Mwita, J. I. (2000). Performance Management Model: A Systems-Based Approach to Public Service Quality. International Journal of Public Sector Management, 13, 19-37. https://doi.org/10.1108/09513550010334461

Nind, M., \& Lewthwaite, S. (2018). Methods That Teach: Developing Pedagogic Research Methods, Developing Pedagogy. International Journal of Research and Method in Education, 41, 398-410. https://doi.org/10.1080/1743727X.2018.1427057

Noe, R. A., Clarke, A. D. M., \& Klein, H. J. (2014). Learning in the Twenty-First-Century Workplace. Annual Review of Organizational Psychology and Organizational Behavior, 1, 245-275. https://doi.org/10.1146/annurev-orgpsych-031413-091321

O’Connor, D., Green, S., \& Higgins, J. P. (2008). Defining the Review Question and Developing Criteria for Including Studies. In Cochrane Handbook for Systematic Reviews of Interventions: Cochrane Book Series (pp. 81-94). Hoboken, NJ: Wiley Blackwell. https://doi.org/10.1002/9780470712184.ch5

Ongori, H., \& Migiro, S. O. (2010). Information and Communication Technologies Adoption in SMEs: Literature Review. Journal of Chinese Entrepreneurship, 2, 93-104. https://doi.org/10.1108/17561391011019041

Owen, S., Palekahelu, D., Sumakul, T., Sekiyono, E., \& White, G. (2018). Systematic Educational Change and Teacher Skill-Building in Developed and Developing Countries: The Importance of Teacher Peer Learning Groups. Teacher Development, 22, 447-463. https://doi.org/10.1080/13664530.2017.1403370

Pearson, M. (2012). Building Bridges: Higher Degree Student Retention and Counselling Support. Journal of Higher Education Policy and Management, 34, 187-199. https://doi.org/10.1080/1360080X.2012.662743

Pittam, J. (1987). The Long-Term Spectral Measurement of Voice Quality as a Social and Personality Marker: A Review. Language and Speech, 30, 1-12. https://doi.org/10.1177/002383098703000101

Poon, J. M. L. L. (2004). Effects of Performance Appraisal Politics on Job Satisfaction and Turnover Intention. Personnel Review, 33, 322-334. https://doi.org/10.1108/00483480410528850

Ramady, M. A. (2010). The Saudi Arabian Economy: Policies, Achievements, and Challenges. Springer Science \& Business Media.

Richman-Hirsch, W. L. (2001). Posttraining Interventions to Enhance Transfer: The Moderating Effects of Work Environments. Human Resource Development Quarterly, 12, 105-120. https://doi.org/10.1002/hrdq.2.abs

Salas, E., Weaver, S. J., \& Shuffler, M. L. (2012). Learning, Training, and Development in Organizations. Oxford: Oxford University Press. https://doi.org/10.1093/oxfordhb/9780199928309.013.0011

Salas, E., Wilson, K. A., Burke, C. S., \& Wightman, D. C. (2006). Does Crew Resource Management Training Work? An Update, an Extension, and Some Critical Needs. Human Factors, 48, 392-412. https://doi.org/10.1518/001872006777724444

Saudi Arabian Monetary Authority (SAMA) (2019). 55th Annual Report. http://www.sama.gov.sa

Segrott, J., McIvor, M., \& Green, B. (2006). Challenges and Strategies in Developing Nursing Research Capacity: A Review of the Literature. International Journal of Nursing Studies, 43, 637-651. https://doi.org/10.1016/j.ijnurstu.2005.07.011 
Sitzmann, T., \& Johnson, S. K. (2012). The Best-Laid Plans: Examining the Conditions under Which a Planning Intervention Improves Learning and Reduces Attrition. Journal of Applied Psychology, 97, 967. https://doi.org/10.1037/a0027977

Sitzmann, T., Kraiger, K., Stewart, D., \& Wisher, R. (2006). The Comparative Effectiveness of Web-Based and Classroom Instruction: A Meta-Analysis. Personnel Psychology, 59, 623-664.

Statista-The Statistics Portal (2020). https://www.statista.com/register/premiumtest

Sutcliffe, K. M., Vogus, T. J., \& Dane, E. (2016). Mindfulness in Organizations: A Cross-Level Review. Annual Review of Organizational Psychology and Organizational Behavior, 3, 55-81. https://doi.org/10.1146/annurev-orgpsych-041015-062531

Taylor, P. J., Russ-Eft, D. F., \& Chan, D. W. L. (2005). A Meta-Analytic Review of Behaviour Modelling Training. Journal of Applied Psychology, 90, 692-709.

https://doi.org/10.1037/0021-9010.90.4.692

Thayer, P. W., \& Teachout, M. S. (1995). A Climate for Transfer Model (No. AL/HRTP-1995-0035). Armstrong Lab Brooks AFB TX Human Resources Directorate.

Tompkins, J. (2002). Strategic Human Resources Management in Government: Unresolved Issues. Public Personnel Management, 31, 95-109.

https://doi.org/10.1177/009102600203100109

Tyler, E. J., Watkins, R. C., Roberts, S. E., Hoerger, M., Hastings, R. P., Hulson-Jones, A., \& Hughes, C. J. (2019). The Collaborative Institute for Education Research, Evidence and Impact: A Case Study in Developing Regional Research Capacity in Wales. Wales Journal of Education, 21, 89-108. https://doi.org/10.16922/wje.21.1.6

Tziner, A., Haccoun, R. R., \& Kadish, A. (1991). Personal and Situational Characteristics Influencing the Effectiveness of Transfer of Training Improvement Strategies. Journal of Occupational Psychology, 64, 167-177. https://doi.org/10.1111/j.2044-8325.1991.tb00551.x

Vallejo, B., \& Wehn, U. (2016). Capacity Development Evaluation: The Challenge of the Results Agenda and Measuring Return on Investment in the Global South. World Development, 79, 1-13. https://doi.org/10.1016/j.worlddev.2015.10.044

Velada, R., Caetano, A., Michel, J. W., Lyons, B. D., \& Kavanagh, M. J. (2007). The Effects of Training Design, Individual Characteristics and Work Environment on Transfer of Training. International Journal of Training and Development, 11, 282-294. https://doi.org/10.1111/j.1468-2419.2007.00286.x

Wexley, K. N., \& Nemeroff, W. F. (1975). Effectiveness of Positive Reinforcement and Goal Setting as Methods of Management Development. Journal of Applied Psychology, 60, 446-450. https://doi.org/10.1037/h0076912

Wilkes, L., \& Jackson, D. (2013). Enabling Research Cultures in Nursing: Insights from a Multidisciplinary Group of Experienced Researchers. Nurse Researcher, 20, 28-34. https://doi.org/10.7748/nr2013.03.20.4.28.e310

Windolf, P. (1986). Recruitment, Selection, and Internal Labour Markets in Britain and Germany. Organization Studies, 7, 235-254.

https://doi.org/10.1177/017084068600700302 